\title{
Scale Development Study: Readiness for Discharge from the Neonatal Intensive Care Unit and Home Care of Premature Infants by Parents
}

\author{
Oznur Tiryaki ${ }^{1}$ and Nursan Cinar $^{2}$ \\ ${ }^{1}$ Department of Nursing, Doctoral Program, Sakarya University - Institute of Health Sciences, Sakarya, Turkey \\ ${ }^{2}$ Department of Paediatric Nursing, Faculty of Health Science, Sakarya University, Sakarya, Turkey
}

\begin{abstract}
Objective: To develop the readiness for hospital discharge scale for mothers and fathers with a premature infant hospitalised in the neonatal intensive care unit and to test the validity and reliability of this scale.

Study Design: A cross-sectional study.

Place and Duration of Study: Sakarya University Education and Research Hospital, Sakarya, Turkey, from February to June 2020.

Methodology: This study was conducted with 136 mothers and 133 fathers, who met the inclusion criteria and agreed to participate in the study. After the content validity of the scale was evaluated, the exploratory and confirmatory factor analysis, reliability analysis (Cronbach Alfa) and test-retest reliability were performed.

Results: As a result of the factor analysis, items of the mother form and the father form were reduced to 22 and 20 , respectively from the scale with 25 items. The confirmatory factor analysis fit indexes were calculated as $\chi^{2} / \mathrm{df}: 1.666, \mathrm{SRMR}: 0.0598$ in mothers and $\chi^{2} / d f: 2.110$, SRMR: 0.0692 in fathers. The Cronbach's Alpha values were 0.911 for mothers and 0.948 for fathers. The test-retest intraclass correlation coefficient was observed as 0.835 for mothers and 0.942 for fathers.

Conclusion: In line with the validity and reliability analyses, it was determined that the mother and father forms of the readiness of the parents of premature infants hospitalised in the NICU for the discharge of infants and home care scale were valid and reliable scales for measuring parents' readiness for discharge.
\end{abstract}

Key Words: Parent, Premature, Neonatal intensive care units, Scale, Development, Reliability and validity.

How to cite this article: Tiryaki O, Cinar N. Scale Development Study: Readiness for Discharge from the Neonatal Intensive Care Unit and Home Care of Premature Infants by Parents. J Coll Physicians Surg Pak 2021; 31(02):171-176.

\section{INTRODUCTION}

The hospitalisation of the premature babies in the neonatal intensive care unit (NICU) for any reason is an unexpected situation and a source of intense stress for parents. ${ }^{1}$ Hospitalisation in the NICU is also a complicated and traumatic process for the infant. ${ }^{2}$ The parents with an infant hospitalised in the NICU, also have many needs in this process. The healthcare team, especially nurses, have the biggest role in determining and meeting primary needs among these needs; and thus ensuring the participation of the family in the care. ${ }^{3}$ Due to the physical environment of the NICU and the complex care needs of infants, parents may have difficulty in participating in the care of their infants. The functioning of the NICU may sometimes acts as a barrier to acquire parental role and take on the responsibility of care.

Correspondence to: Dr. Oznur Tiryaki, Sakarya University, Institute of Health Sciences, Sakarya, Turkey

E-mail: oznuritiryaki@gmail.com

Received: October 26, 2020; Revised: January 29, 2021;

Accepted: February 11, 2021

DOI: https://doi.org/10.29271/jcpsp.2021.02.171
Therefore, infant can be discharged before parents are ready enough for discharge. ${ }^{4}$ Ineffective discharge planning may lead to failure to meet the home care needs of the infant, the emergence of new health problems, and repeated hospitalisations. ${ }^{5}$ In order for discharged premature infants to receive adequate care and maintain their health outside the hospital, the family should be able to take care of their infants independently and be able to distinguish between negative or unusual situations. The parents must acquire the necessary knowledge and skills to meet the baby's home care needs prior to discharge and discharge planning should be carried out thereafter ${ }^{6-8}$

The aim of this study was to develop the mother and father forms of the readiness of the parents of premature infants hospitalised in the NICU for the discharge of infants and home care scale, and to test its validity and reliability.

\section{METHODOLOGY}

This methodological study included a cross-sectional survey to mother and father of premature infants hospitalised in the NICU for the discharge of infants and home care scale. 
It was planned to develop a separate scale for the mother and father in order to make the mother a self-care agent in the care of babies and to question the breastfeeding status of the infant. As a result of evidence-based protocols, applications, experience of researchers, and literature research on infant care in order to measure parents' readiness for the discharge of their infants from the NICU and then home care, item pools were created separately for mothers and fathers. ${ }^{9-12}$ The scale drafts were sent to 21 individuals, who are experts in their field; and feedback was obtained. The experts consisted of 9 academician nurses, 10 NICU nurses, and 2 newborn sub-branch experts.

For each item, the content validity index (CVI) was used for the evaluation of expert opinions. The CVI was calculated by taking the average of content validity ratios (CVR) to determine whether the experts considered that item necessary. They were asked to score each statement between 1-4 points (1 point: inappropriate, 2 points: slightly appropriate, 3 points: appropriate, 4 points: completely appropriate) and to clearly write their comments and suggestions on each item. In line with the opinions of the experts, the items were reviewed and necessary arrangements were made. It is concluded that the content validity of the items with a CVR (0.42) value is ensured. CVI was found to be 0.992 in the average of CVR rates. Since CVI $\geq$ CVO $(0.42)$, the content validity of the whole scale was found to be statistically significant. ${ }^{9}$ Furthermore, the scale draft prepared before the application was evaluated by two Turkish language and literature teachers; and final corrections were made. A preliminary study was conducted with 10 mothers and 10 fathers, who met the inclusion criteria, before starting to collect data for the comprehensibility of the items of the scale draft. The pilot study group was not included in the sample group.

The study was conducted in a training and research Hospital affiliated to the Ministry of Health between February 3 and June $30,2020$. All parents ( $\mathrm{N}: 173)$ of premature infants hospitalised in the NICU between the dates of study conducted in the relevant hospital constituted the population of the study. Inclusion criteria were: premature infants born between 24 and 37 weeks of gestation and at least one day of hospitalisation in the NICU. The sample size is recommended to be at least 5-10 times the number of scale items in scale development. ${ }^{9}$ In this study, 136 mothers and 133 fathers constituted the sample group.

The data were collected using the "Mother/Father Introductory Information Form", which was prepared by the researchers and consisted of 14 questions, and the draft form for the mother and father of premature infants hospitalised in the NICU for the discharge of infants and home care scale, which was developed by the researchers to measure the readiness of parents with premature infants for discharge from the NICU. ${ }^{10,11}$ It includes the questions regarding mother's age, father'sage, educational status, employment status, family type, planned pregnancy status, method of delivery, gender of the infant, the week of birth, birth weight, the number of days of hospitalisation in NICU, visit frequency for infants, information getting status about the infants and readiness for motherhood.
The data of the participants were transferred to IBM SPSS Statistics 23 and IBM SPSS AMOS 23 programmes and analysed. Descriptive statistics ( $n, \%$, mean, standard deviation) were used for categorical and quantitative variables. The content validity ratio and the content validity index were used in the evaluation of the scores given by the experts. In scale development, first the exploratory factor analysis (EFA) and then the confirmatory factor analysis (CFA) were performed, and the Cronbach's Alpha values were analysed for scale reliability. Furthermore, as a result of phone calls again with 39 mothers and 38 fathers, three weeks later for test-retest reliability, the test retest reliability was evaluated by the intraclass correlation (ICC) test. Statistical significance was accepted at $p<0.05$.

\section{RESULTS}

It was observed that the mean age of 136 mothers, who participated in the study, was $29.25 \pm 5.4$ years, the mean birth week of their infants was $30.78 \pm 3.19$, the mean birth weight was $1576.07 \pm 666.47$ grams, the number of days of hospitalisation of infants in the NICU was $36.89 \pm 30.85$, and 76 (55.9\%) of them were baby girls. It was observed that the mean age of 132 fathers, who participated in the study, was $33.31 \pm 5.85$ years, the mean birth week of their infants was $30.65 \pm 3.28$ weeks, the mean birth weight was $1569.51 \pm 649.44$ grams, the number of days of hospitalisation of infants in the NICU was $38.59 \pm 33.02$, and $80(60.2 \%)$ of them were baby girls (Tablel).

Kaiser Meyer Olkin (KMO) value was calculated as 0.890 for the mother form (MF) and 0.904 for the father form (FF). Mother and Father $p<0.001$ for both.

For mothers, while the care practices subscale of the scale explained $29.975 \%$ of the total variance, the hygienic care subscale explained $19.701 \%$ of the total variance, the perception of general situation subscale explained $12.783 \%$ of the total variance, and the feeding subscale explained $10.426 \%$ of the total variance. These four factors together explained 72.886 of the total variance. For fathers, the hygienic care subscale of the scale explained $27.189 \%$ of the total variance, the support for nutrition and care subscale explained $23.787 \%$ of the total variance, and the care practices subscale explained $16.389 \%$ of the total variance. These three factors together explained 67.366 of the total variance (Table II).

In the first stage, four factor dimensions as latent variable (feeding, perception of general situation, hygienic care, care practices) for mothers, three factor dimensions as latent variable (support for nutrition and care, hygienic care, care practices) for fathers, and the statements that constituted these factors as indicator variable are presented in the 1st order CFA models.

In the second stage, the maximum likelihood method, which is frequently used in structural equation models and provides reliable results even when the data are not normally distributed, was used in model estimation. It was aimed to estimate the parameters including the errors of observed variables, variances of latent variables, and the regression coefficients for the paths from latent variables to the observed variables. 
Table I: Demographic information of mothers and fathers.

\begin{tabular}{|c|c|c|}
\hline Variables & Mother $\mathbf{n}(\%)$ & Father n (\%) \\
\hline $\begin{array}{l}\text { Education status } \\
\text { Primary education } \\
\text { High school } \\
\text { License } \\
\text { Graduate }\end{array}$ & $\begin{array}{l}31(22.8) \\
52(38.2) \\
50(36.8) \\
\quad 3(2.2)\end{array}$ & $\begin{array}{c}24(18.0) \\
52(39.1) \\
48(36.1) \\
9(6.8)\end{array}$ \\
\hline $\begin{array}{l}\text { Employment status } \\
\text { Yes } \\
\text { No }\end{array}$ & $\begin{array}{r}35(25.7) \\
101(74.3)\end{array}$ & $\begin{array}{c}124(93.2) \\
9(6.8)\end{array}$ \\
\hline $\begin{array}{l}\text { Family type } \\
\text { Core } \\
\text { Large } \\
\text { Broken }\end{array}$ & $\begin{array}{r}113(83.1) \\
21(15.4) \\
2(1.5)\end{array}$ & $\begin{array}{r}116(87.2) \\
17(12.8) \\
-\end{array}$ \\
\hline $\begin{array}{l}\text { Income status } \\
\text { Less than } 2020 \text { Türk Lirası } \\
\text { Equal to } 2020 \text { Türk Lirası } \\
\text { More than } 2020 \text { Türk Lirası }\end{array}$ & $\begin{array}{l}28(20.6) \\
84(61.8) \\
24(17.6)\end{array}$ & $\begin{array}{l}19(14.3) \\
81(60.9) \\
33(24.8)\end{array}$ \\
\hline $\begin{array}{l}\text { Frequency of visiting your baby } \\
\text { Once a day } \\
\text { Once a week } \\
3 \text { hours apart } \\
\text { I've never seen my baby }\end{array}$ & $\begin{array}{l}88(64.7) \\
15(11.0) \\
13(9.6) \\
20(14.7)\end{array}$ & $\begin{array}{l}69(51.9) \\
30(22.6) \\
10(7.5) \\
24(18.0)\end{array}$ \\
\hline $\begin{array}{l}\text { The person who receives information about her baby } \\
\text { Doctor } \\
\text { Nurse } \\
\text { I did not get information }\end{array}$ & $\begin{array}{r}120(88.2) \\
16(11.8) \\
-----\end{array}$ & $\begin{array}{c}120(90.2) \\
12(9.0) \\
1(0.8)\end{array}$ \\
\hline $\begin{array}{l}\text { Gender of the baby } \\
\text { Famale } \\
\text { Male }\end{array}$ & $\begin{array}{l}76(55.9) \\
60(44.1)\end{array}$ & $\begin{array}{l}80(60.2) \\
53(39.8)\end{array}$ \\
\hline & Mother Mean \pm SD & Father Mean \pm SD \\
\hline Age & $29.25 \pm 5.40$ & $33.31 \pm 5.85$ \\
\hline Baby's birth week & $30.77 \pm 3.19$ & $30.65 \pm 3.28$ \\
\hline Baby's birth weight & $1576.07 \pm 666.47$ & $1569.51 \pm 649.44$ \\
\hline Number of days spent in NICU & $36.89 \pm 30.85$ & $38.59 \pm 33.02$ \\
\hline
\end{tabular}

A two-way relationship was established between the error terms of the questions $I 13$ to $I 16, I 19$ and $I 20$ in the readiness of the mother with a premature infant in the neonatal intensive care unit for discharge and home care scale with the highest modification indices, and the questions 13,14 , $110,111,114,115$ in the readiness of the father with a premature infant in the neonatal intensive care unit for discharge and home care scale in order to improve the fit indices. Furthermore, the relational construct was established between the dimensions to determine the expected covariance between the dimensions. The relationships between the dimensions were shown in Figures 1 and 2 .

When the fit values obtained were examined, the values of $\chi 2 / d f(1.666)$, CFI (0.954), SRMR (0.0598) for mothers and $\chi 2 / d f(2.110)$, CFI (0.916), SRMR (0.0692) for fathers were obtained. One of the most frequently used criteria during the evaluation of scale reliability is Cronbach's Alpha, which is a measure of internal consistency. The Cronbach's Alpha value of the mother form scale was calculated as 0.911 (subscales, feeding: 0.793; perception of general situation: 0.819; hygienic care: 0.873 ; care practices: 0.968 ), and the Cronbach's Alpha value of the father form scale was calculated as 0.948 (subscales, support for nutrition and care: 0.920 ; hygienic care: 0.928 ; care practices: 0.826$)$. Furthermore, the ICC value was determined as 0.835 for mothers and 0.942 for fathers for the scale test retest reliability.

In the 7-point Likert scale consisting of 22 positive items for MF (Apendix 1) and 20 positive items for FF (Apendix 2) of the scale developed to evaluate parents' readiness for discharge, each item is scored between 1 and 7 from not being ready complete readiness, and the total scale score is obtained by the sum of scores. While the minimum and maximum scores obtained from the MF are 22 and 154, respectively, the minimum and maximum scores obtained from the FF are 20 and 140, respectively. High scores indicate that parents are highly ready for discharge. Each item of the scale can be evaluated separately or calculated over the total score. The validity and reliability of the scale can be applied in those with one or more parenting experiences. Furthermore, the scale can be applied for the parents with premature infants hospitalisation in the NICU for at least 24 hours, and in the period upto 24 hours before discharge at the earliest. It can be used in all parents with premature infants in the NICU. While the MF and FF of the scale can be applied to both parents of the infant; only MF or only FF can also be applied.

Table II: Scale factors for MF and FF. 


\begin{tabular}{|c|c|c|c|c|c|c|c|c|c|}
\hline MF dimensions & Items & Loads & $\begin{array}{l}\text { Eigen } \\
\text { values }\end{array}$ & $\begin{array}{l}\text { Total } \\
\text { variance } \\
\text { explained }\end{array}$ & FF dimensions & Items & Loads & $\begin{array}{l}\text { Eigen } \\
\text { values }\end{array}$ & $\begin{array}{l}\text { Total } \\
\text { variance } \\
\text { explained }\end{array}$ \\
\hline Feeding & $\begin{array}{l}11 \\
12 \\
13\end{array}$ & $\begin{array}{l}.804 \\
.810 \\
.784 \\
\end{array}$ & 2.294 & 10.426 & \multirow[b]{2}{*}{$\begin{array}{l}\text { Support for feeding } \\
\text { and Care }\end{array}$} & \multirow{2}{*}{$\begin{array}{l}11 \\
12 \\
13 \\
14 \\
15 \\
16 \\
17 \\
18\end{array}$} & \multirow{2}{*}{$\begin{array}{l}.753 \\
.822 \\
.603 \\
.653 \\
.654 \\
.674 \\
.709 \\
.662\end{array}$} & \multirow[b]{2}{*}{4.757} & \multirow[b]{2}{*}{23.787} \\
\hline $\begin{array}{l}\text { General situation } \\
\text { perception }\end{array}$ & $\begin{array}{l}14 \\
15 \\
16 \\
17\end{array}$ & $\begin{array}{l}.679 \\
.715 \\
.760 \\
.839\end{array}$ & 2.812 & 12.783 & & & & & \\
\hline Hygienic care & $\begin{array}{l}18 \\
19 \\
110 \\
111 \\
112 \\
113 \\
114\end{array}$ & $\begin{array}{l}.702 \\
.644 \\
.815 \\
.830 \\
.796 \\
.635 \\
.629\end{array}$ & 4.334 & 19.701 & Hygienic care & $\begin{array}{l}\text { I9 } \\
\mathrm{I} 10 \\
\mathrm{I} 11 \\
\mathrm{I} 12 \\
\mathrm{I} 13 \\
\mathrm{I} 14 \\
\mathrm{I}\end{array}$ & $\begin{array}{l}.721 \\
.861 \\
.864 \\
.818 \\
.881 \\
.732 \\
.477\end{array}$ & 5.438 & 27.189 \\
\hline Care practices & $\begin{array}{l}115 \\
116 \\
117 \\
118 \\
119 \\
120 \\
121 \\
122\end{array}$ & $\begin{array}{l}.897 \\
.909 \\
.622 \\
.902 \\
.894 \\
.852 \\
.912 \\
.938\end{array}$ & 6.595 & 29.975 & Care practices & $\begin{array}{l}116 \\
117 \\
118 \\
119 \\
120\end{array}$ & $\begin{array}{l}.725 \\
.838 \\
.677 \\
.614 \\
.537\end{array}$ & 3.278 & 16.389 \\
\hline
\end{tabular}

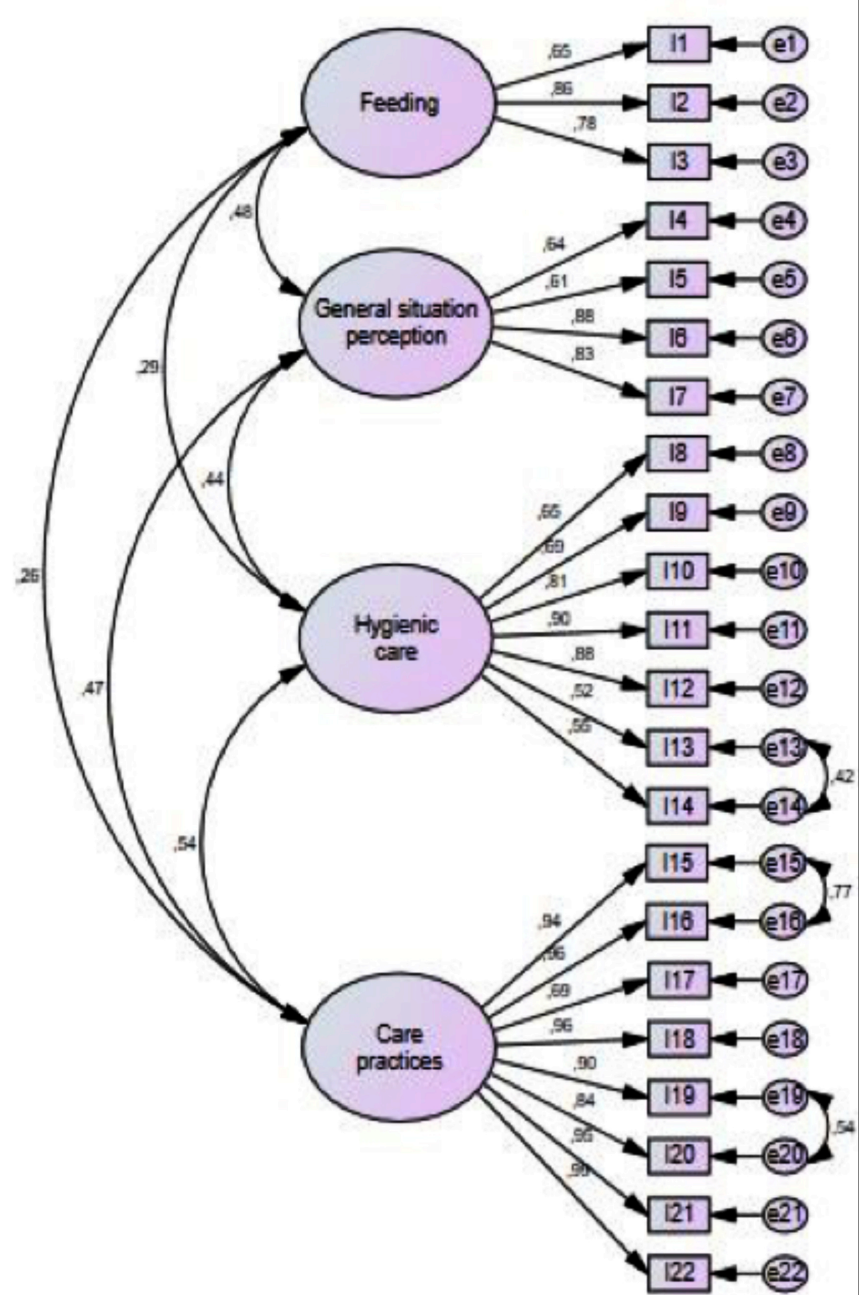

Figure 1: Mother form 4 sub-dimensions 1st degree DFA model.

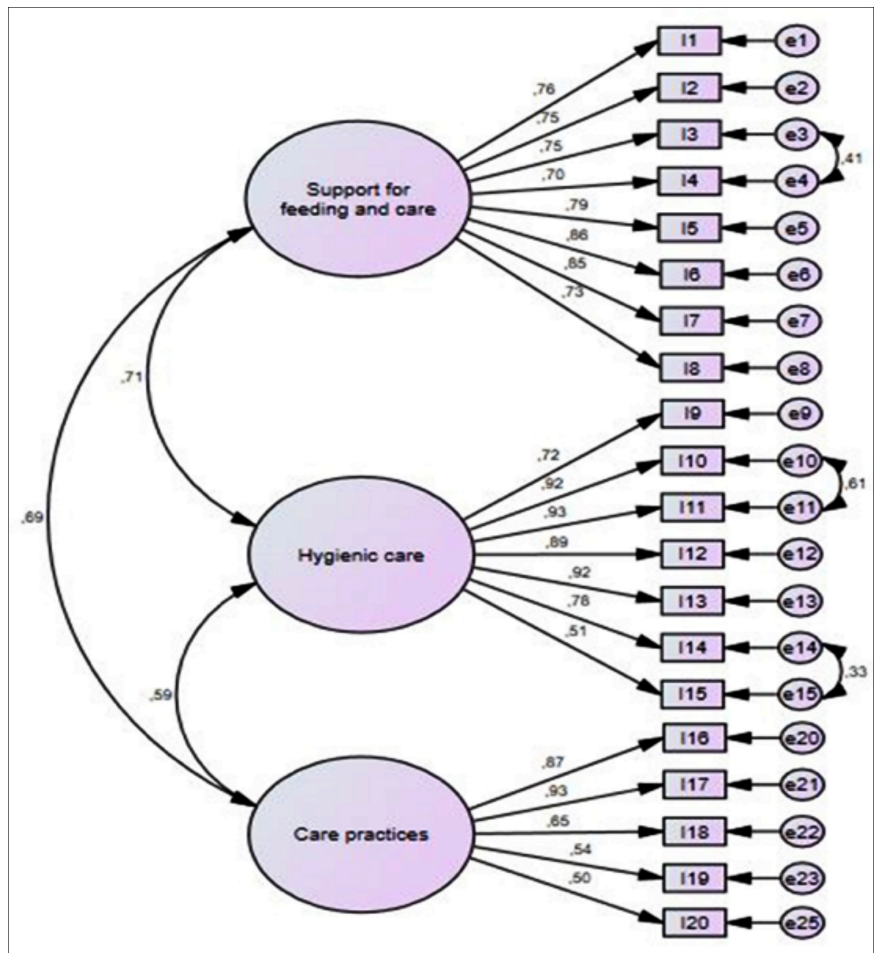

Figure 2: Father form 4 sub-dimension 1st degree DFA model.

\section{DISCUSSION}

When the parents are unable to identify and perform their role in neonatal care after discharge, then unwanted complications can occur. It will increase the incidence of early rehospitalisations. The hospital-to-home transition period, which is very critical for parents, needs to be well planned, 
and effective discharge preparation should be made. ${ }^{13}$ The points to consider in making decision on readiness can be mentioned as functional competence, readiness for self-care at home, the presence of social support, easy access to health services, adaptation to the infant and parenthood, and having information about post-discharge. The fact that the patients/parents feel ready for discharge is an important factor in making decision on discharge. ${ }^{14}$

In the study, the content validity and construct validity of the scale were examined in order to test its validity; the mother and father forms of which were prepared separately. ${ }^{15}$ As a result of $\mathrm{CVI}$ analysis between 21 expert opinions, it was observed that they agreed on the content of the items. The KMO and Bartlett tests were performed to find out whether the scale was suitable for factor analysis. The KMO measure is expected to be more than 0.80 for a good factor analysis (mother KMO 0.890, father KMO 0.904). It is observed that the sample size was large enough to apply factor analysis to the data. As a result of the Bartlett sphericity test, it was concluded that there were significantly high relationships between the variables and that the data were suitable for applying factor analysis $(p<0.05))^{9,16}$ In the study, the KMO test and the Bartlett sphericity test were also observed to be significant.

In the study, the EFA was applied, and the principal components method was preferred as the factor extraction method. As a result of the factor analysis, the number of items, which was 25 for mothers, reduced to 22 due to low factor loads; and the number of items, which was 25 for fathers, reduced to 20 . It was determined that while mothers were gathered in four factors, fathers were gathered in three factors, and the factor loads were over than 0.500 . The variance should exceed $50 \%$ of the total variance. Thus, the fact that the factor structure created is half/more than half of the total variable variance indicates that it has a representative ability. ${ }^{17,18}$ When the results obtained for the mothers were examined, it was observed that the 4-factor structure with 22 statements of the readiness of the mother with a premature infant in the neonatal intensive care unit for discharge, and home care scale generally fitted well (Figure 1 ). When the results obtained for the fathers were examined, it was observed that the 3-factor structure with 20 statements of the readiness of the father with a premature infant in the neonatal intensive care unit for discharge, and home care scale generally fitted well (Figure 2).

In the test-retest method of the scale, it is necessary to apply the measuring tool for the second time (a time period that is long enough to prevent remembering the first answer, but short enough not to cause significant changes in the feature to be measured). It is usually enough that the time between these two measurements is between two and four weeks. ${ }^{19,20}$ The ICC was used in test-retest analysis. The fact that the ICC value was 0.835 for mothers and 0.942 for fathers, indicated that the test-retest reliability of the scale was high. The lack of a measuring tool evaluating the readiness of the parents of premature infants staying in the hospital for discharge in the literature, and the elimination of this shortcoming with the mother and father forms of the readiness of the parents with premature infants in the neonatal intensive care unit for discharge and home care scale, which were developed separately for both mother and father, will make significant contributions to nursing practices in the units. Furthermore, the scale can be used by translating it into different national and international languages.

\section{CONCLUSION}

The developed readiness scale, is a reliable measuring tool in assessing the readiness of the parents of premature infants hospitalised in the NICU for the discharge and home care of their neonates. Furthermore, the fact that the scale is separate for both mother and father allows for their evaluation separately. The readiness of parents can be determined with the readiness for discharge scale prepared for mothers and fathers. Nurses can provide education, counselling and support to the parents about the items with a low score.

\section{DISCLOSURE:}

The authors disclosed that this study is derived from a doctoral thesis.

\section{ETHICAL APPROVAL:}

Prior to the study, approval was obtained from non-pharmaceutical interventional research ethics committee (13/01/2020-14) in a university's faculty of medicine, and written permissions were obtained from the administration of the Hospital where the study was conducted, and parents.

\section{PATIENTS' CONSENT:}

All participants were informed that the data related to this research would be used only for publication.

\section{CONFLICT OF INTEREST:}

The authors declared no conflict of interest.

\section{AUTHORS' CONTRIBUTION:}

OT, NC: Study design, data collection and processing, analysis and interpretation, preparation of the manuscript, critical review and revision.

\section{REFERENCES}

1. Albayrak $S$, Büyükgöneç LA. The adaptation of the empowerment of parents in the intensive care-neonatology scale to turkish: A validity and reliability study. J Educ Res Nursing 2019; 16(4):313-23. doi:10. 5222/HEAD.2019.313.

2. Tutar Güven Ş, Kaya A, İşler Dalgıç A. Individualized supportive developmental care applications for preterm infants according to gestational weeks. DEUHFED 2019; 12: 283-93. 
3. Küçükoğlu S, Aytekin A, Gülhaş NF. Identifying the needs of mothers whose babies were admitted to neonatal Intensive care units. J Edu Res Nurs 2015; 12:182-8. doi:10.5222/ HEAD.2015.182.

4. Larsson C, Wagström U, Normann E, Blomqvist YT. Parents experiences of discharge readiness from a Swedish neonatal intensive care unit. Nursing Open 2017; 4:90-5. doi: 10.1002/nop2.71.

5. Kuşeli Dost S, Kaya H. Validity and reliability of turkish version of the pretest intensive care nurses' discharge planning perceptions scale. Florence Nightingale J Nursing 2015; 23:195-202.

6. McGowan EC, Du N, Hawes K, Tucker R, O’Donnell, Vohr B. Maternal mental health and neonatal intensive care unit discharge readiness in mothers of preterm infants. J Pediatr 2017;184:68-74. http://dx.doi.org10.1016/j.jpeds.2017. 01.052 .

7. Batman D, Çoban A. The effect of delayed umbilical cord clamping and cord milking on premature newborns. J Health Sci Kocaeli University 2019; 5:54-59. doi:10.30934/ kusbed.475344.

8. Galeano SPO, Marín SCO, Semenic S. Preparing for postdischarge care of premature infants: Experiences of parents. Invest Educ Enferm 2017; 35:100-108. doi: 10.17533/udea.iee.v35n1a12.

9. Alpar R. With Examples from sports, health and educational sciences, applied statistics and analysis steps in validity-reliability-SPSS. Ankara: Detay Yayıncılık, 3. Baskı 2014; 529.

10. Tiryaki Ö, Zengin H, Çınar N, Umaroğlu M, Latour J. Turkish adaptation and validation of the empowerment of parents in the intensive care (EMPATHIC-30) questionnaire to measure parent satisfaction in neonatal intensive care units. Front in Pediatrics 2020; 8:421. doi: 10.3389/fped. 2020.00421.

11. Boykova M. Transition from hospital to home in parents of preterm infants: Revision, modification, and psychometric testing of the questionnaire. J Nursing Measurement 2018;
26(2):296-310. doi: 10.1891/1061-3749.26.2.296.

12. Yalnızoğlu Çaka S, Çınar N. Development of the scale for readiness of pregnant women to hygienic care of the newborn, and its validity and reliability study. Deuhfed 2020; 13: 10-8.

13. Moradi S, Arshdi-Bostanabad M, Seyedrasooli A, Tapak L, Valizadeh $\mathrm{S}$. The effect of empowerment program on maternal discharge preparation and neonatal length of hospital stay: A randomised controlled trial. Iranian J Nursing Midwifery Res 2018; 23(3):172-7. doi: 10.4103/ ijnmr.IJNMR_110_17.

14. Akın B, Şahingeri M. Validity and reliability of turkish version of readiness for hospital discharge scale-new mother form (RHD-NMF). J Anatolia Nursing Health Sci 2010; 13: 7-14.

15. Karakoç FY, Dönmez L. Basic principles of scale development. Tıp Eğitimi Dünyası 2014; 40:40-9.

16. Clark LA, Watson D. Constructing validity: New developments in creating objective measuring. American Psychological Association 2014; doi: http://dx.doi.org/ 10.1037/pas0000626. Date of access:30 October 2020.

17. Ateş C, Kaymaz Ö, Kale M, Tekindal MS. Comparison of test statistics of nonnormal and unbalanced samples for multivariate analysis of variance in terms of type-I error rates. Computational and Mathematical Methods in Medicine 2019; 1-8. doi.org/10.1155/2019/2173638.

18. Alavi M, Visentin DC, Thapa DK, Hunt GE, Watson R, Clear M. Exploratory factor analysis and principal component analysis in clinical studies: Which one should you use? J Adv Nurs 2020; 00:1-4. http://doi.org/10.1111/jan.14377.

19. Aktürk Z, Acemoğlu H. Reliability and validity in medical research. Dicle Medical J 2012; 39:316-19. doi: 10.5798/ diclemedj.0921.2012.02.0150.

20. Liebe U, Meyerhoff J, Hartje V. Test-retest reliability of choice experiments in environmental valuation. Environ Resour Econ. 2012; 53:389-407. DOI 10.1007/s10640012-9567-1. 